\title{
ETNOGRAFIA SONORA NA CIDADE: ALGUMAS CONTRIBUIÇÕES METODOLÓGICAS ACERCA DO REGISTRO SONORO NA PESQUISA DE CAMPO
}

\author{
Priscila Farfan Barroso ${ }^{1}$ \\ Stéphanie Ferreira Bexiga ${ }^{2}$ \\ Ana Luiza Carvalho da Rocha (orientação) ${ }^{3}$
}

\section{O entendimento da imagem sonora como imagem simbólica no pré-campo}

A proposta deste ensaio é discutir questões acerca da construção da imagem sonora a partir de um processo metodológico que vem sendo desenvolvido no Banco de Imagens e Efeitos Visuais (PPGAS/UFRGS) há cerca de dez anos. Nessa tarefa, temos como pano de fundo as reflexões oriundas do Grupo de Trabalho sobre Etnografia Sonora no interior do BIEV no ano de 2008, principalmente. ${ }^{4}$ Para iniciar tal assunto, no entanto, é preciso esclarecer ao leitor o que entendemos pelo conceito de imagem sonora e da especificidade da metodologia a qual aderimos nesse projeto.

No interior da linha de estudos da Antropologia Urbana e Sociedades Complexas, trabalhamos, enquanto grupo de pesquisa, com a problemática da "duração" (Bachelard, 1988) nas cidades moderno-contemporâneas. Nesta temática, adotamos como um de nossos métodos de pesquisa a "etnografia de rua" (Eckert; Rocha, 2003) que consiste em caminhadas constantes pelo cenário da vida urbana, através das quais observamos as diversas imagens (visuais e sonoras) evocadas pelos indivíduos que habitam esses lugares. Dessa observação sistemática, escrita e reescrita em diários de campo e descrições etnográficas, se constroem as interpretações das aprendizes de Antropologia sobre o cotidiano do viver urbano.

Nossos trabalhos, que compõe esta área de estudos, procedem de uma metodologia que envolve três etapas: pré-campo, onde está colocada nossa preparação em termos de roteiros e da forma como imaginamos gravar sonoridades; o campo, esse próprio "estar-lá" do qual se refere

\footnotetext{
${ }^{1}$ Universidade Federal do Rio Grande do Sul, Brasil.

${ }^{2}$ Universidade Federal do Rio Grande do Sul, Brasil.

${ }^{3}$ Universidade Federal do Rio Grande do Sul, Brasil.

4 O Grupo de Trabalho sobre Etnografia Sonora se desenvolve sob a coordenação de Ana Luiza Carvalho da Rocha (coordenadora do projeto BIEV) e Viviane Vedana (Pesquisadora associada ao BIEV), com a participação das bolsistas Priscila Farfan Barroso (Bolsa IC/FAPERGS) e Stéphanie Ferreira Bexiga (Bolsa IC/CNPq).
} 
Geertz; e o pós-campo, onde voltamos carregadas de expressões sonoras que dialogam e colocam em questão nossas escolhas anteriores de captação. Para o caso deste estudo, trataremos especificamente da primeira etapa para que possamos questionar, em conjunto, tais formas de interpretar as sonoridades do fenômeno urbano.

Para analisar como o pré-campo é pensado, e por sua vez consolidado, estudaremos como o etnógrafo "absorve" a cidade em sua experiência. Nós, aprendizes de Antropologia, somos igualmente habitantes da cidade. Em nossas trajetórias, somos habitadas por diversas imagens simbólicas - que por meio dos sons, cheiros, olhares compõem as formas sensíveis da vida social (Sansot, 1996) - através das quais o pensamento se processa. ${ }^{5}$ Ao ir a campo, antes de levar o equipamento audiovisual, também com-partilhamos das imagens simbólicas com os indivíduos dos grupos pesquisados, e essas formas expressivas (Dawsey, 2000) são registradas em diários de campos e descrições etnográficas.

No âmbito da "etnografia sonora" (Rocha, Vedana, 2007), em campo damos atenção às imagens mentais evocadas por sonoridades - já que a nossa escuta está sensibilizada por esta área de estudo - as quais antes de pensá-las conceitualmente, fazem parte dos "jogos da memória" (Eckert; Rocha, 2005). Então, ao elaborar um roteiro de gravação, tanto essas imagens que nos habitam há muito tempo como àquelas que percebemos, pensamos e descrevemos após nossas saídas de campo - já através de um outro olhar e outro ouvir - vem à tona. É, na verdade, através de uma "imaginação criadora" (Bachelard, 1996) que nós imaginamos e construímos conhecimento científico ao pensar nas formas de captação dessas sonoridades, indagando-nos em como construir esse encontro etnográfico ${ }^{6}$.

Dessa forma, questionamos: o que revelam sobre a cidade as diversas melodias de chamamentos dos vendedores ambulantes entrelaçadas com as conversas entre passantes/clientes? E o estudo das descontinuidades rítmicas do assobiar dos pássaros e dos vaivens de carros associados a rápidas interações que ocorrem em cantos dos bairros? Através dos passos na cidade, percebemos e observamos esses conjuntos de imagens sonoras que, como "formas sensíveis da vida social" (Sansot, 1996), podem ser apreendidas nos cheiros, nos sons,

\footnotetext{
5 Adotamos, em concordância com autores como Bachelard e Durand, que o pensamento pensa através de imagens.

6 “O espaço convida à ação, e antes da ação a imaginação trabalha.” (Bachelard, 1996, p.31). Na adesão a essa perspectiva, lembramos a crítica feita por Rocha (2001, p.13) ao cartesianismo por ter afastado a "imaginação criadora" do processo de construção de operações mentais com as quais o homem pensa e vive o mundo.
} 
nos olhares e nas sensações diversas que nos atravessam ao percorrer a cidade através da etnografia.

Porém, como se dá a relação entre isto que acabamos de dizer sobre as imagens percebidas e compartilhadas com outros indivíduos no contexto urbano, e a construção de uma imagem sonora? Aliás, de que maneira isso se relaciona com a metodologia a qual adotamos?

A partir da adesão a uma interpretação fenomenológica da vida social, entendemos que a investigação da imagem sonora nutre-se do conhecimento construído pelo pensamento humano em sua vida cotidiana (Corcuff, 2001:91 apud Schutz, 1987), entretanto é através das interpretações que transcendem esse caráter cotidiano, do senso comum, que construímos procedimentos metodológicos para compreender a vida social e contribuir para o conhecimento científico. Por esta razão, entendemos a imagem sonora como um objeto de investigação da Antropologia, uma vez que as sonoridades não só expressam simbolismos como evocam representações etnográficas.

No âmbito dos estudos de "etnografia sonora" (Rocha e Vedana, 2007) na e da cidade, não entendemos o som como caos urbano - associação recorrente no contexto citadino. Nas grandes cidades, caracterizadas pelos seus aspectos de heterogeneidade e complexidade (Velho, 1980), o som torna-se um componente da fragmentação desagregadora do urbano, um elemento caótico que cada vez mais dissocia o sujeito de seu mundo social, podendo, a cidade, provocar no indivíduo uma "atitude blasé". Ao efetuar uma ruptura com essa noção a respeito das sonoridades que nos rodeiam, preocupamo-nos em pensar o som para além de uma interpretação simplista, recorrente no senso comum $^{8}$, entendendo-o como "imagem" (Chion, 2004) capaz de revelar as associações, a constante troca do sujeito com seu mundo cósmico e social.

\footnotetext{
${ }^{7} \mathrm{O}$ esforço do grupo ao propor o procedimento metodológico que apresentaremos aqui é lidar com uma imagem sonora - fixada num suporte para que possa ser ouvida muitas vezes - que não é um dado imediato do mundo social. Ou seja, faz parte de um conhecimento que "nunca é imediato e pleno" (Bachelard, 1996), e se constrói através de desconstruções e novas construções epistemológicas, ultrapassando obstáculos erguidos diante do pesquisador que busca conhecer um fenômeno para além de suas impressões primeiras. Dessa forma, é desde o nosso lugar enquanto aprendizes de Antropologia que falamos em imagem sonora, nosso objeto de estudo; assim, muito mais através de nossas interpretações. Essas imagens simbólicas evocadas pelas sonoridades são entendidas como parte integrante da vida social e urbana, uma vez que ela também perpassa nossas trajetórias como sujeitos da cidade.

8 "Carros em lugares proibidos, pedestres atravessando fora da faixa, pessoas caminhando muito devagar, outras correndo contra o relógio. Moradores de rua dormindo nas calçadas, enquanto vendedores oferecem em voz alta "fábrica de calcinhas", "corte de cabelo" e "Shrek dublado em DVD". Aos gritos, acrescentam-se buzinas e xingamentos no trânsito. Bem-vindo ao Centro, um rali com direito a trilha sonora caótica". ZH Centro, jornal de Porto Alegre-RS, agosto de 2007.
} 
É a partir desse viés que falamos das imagens simbólicas evocadas pelo som. Escutamos o desenrolar das cenas nas ruas através desses contornos sonoros, e notamos que em nossas periódicas saídas a campo certas expressões sonoras são recorrentes nesses lugares. Assim, já temos pistas de "pontos de escuta" 9 em que se pode pensar os posicionamentos em campo a fim de gravar essas sonoridades tão evocativas dos cenários urbanos estudados. Através do posicionamento metodológico - vinculado ao posicionamento epistemológico -, depois de escutar e descrever inúmeras vezes, efetuamos um distanciamento perceptivo das expressões sonoras do campo, o qual também nos permite pensá-las em seu caráter objetal. ${ }^{10}$

No entanto, não se trata apenas de escutar sons. A escuta, a qual temos nos referido, também é provocada, sensibilizada, construída. No percurso entre a imaginação e a gravação, perpassamos diferentes "escutas" (Chion, 2004), as quais poderiam ser pensadas em termos de suas etapas e as "rupturas epistemológicas" (Bachelard, 1996) necessárias para prosseguir num conhecimento científico que também faz parte do procedimento metodológico ao qual aderimos. Nesse trajeto descontínuo - entre escutas, rupturas e novas escutas -, construímos nossas hipóteses sobre o objeto de pesquisa.

Assim, trazemos aqui descrições oriundas de nossos diários de campo onde, já sensibilizadas com a escuta, interpretamos a cidade através de suas sonoridades. O primeiro fragmento de texto está relacionado à pesquisa no bairro Tristeza, zona sul de Porto Alegre/RS (Brasil), sobre as formas de sociabilidade e sua relação com a ambiência de bairro. Já o segundo pertence à pesquisa sobre o cotidiano dos vendedores ambulantes e suas redes de solidariedade na Rua Voluntários da Pátria, no centro da mesma cidade. Estes breves fragmentos podem nos

\footnotetext{
${ }^{9}$ São prováveis pontos - lugares - em que o pesquisador escolhe para se posicionar ao captar as sonoridades relevantes para o campo estudado. Esse é um importante recurso metodológico, uma vez que antes de ir a campo se pensa em "mapear" onde estão as sonoridades que serão gravadas em campo, e assim, o pesquisador consegue ser mais preciso em seu trabalho.

${ }^{10}$ As imagens sonoras compõem nossos "jogos da memória" (Rocha, Eckert, 2005) e, ao perceber recorrências simbólicas através de nossas escutas - tanto em campo como aquelas referentes ao que foi gravado -, concebemo-las como possíveis de representações etnográficas (ao fazer seu registro, ao descrevê-las em diários, pensando como estão relacionadas às formas de vida de determinados lugares, etc.). Percebemos, então, que ao fazerem parte desses jogos, as imagens simbólicas fazem parte das representações coletivas, possibilitando-nos torná-las objeto de representações etnográficas. Seu caráter objetal, aliás, vem justamente disto, pois "uma vez que o som repouse na memória auditiva, ele não é mais um acontecimento, mas um objeto, não estando mais associado a um momento particular." (ROCHA, VEDANA; Manual de Orientação de Coleções Etnográficas Sonoras - elaborado no interior do Biev para orientar as questões de construção da imagem sonora e da adesão a uma etnografia sonora. 2007, p14).
} 
ajudar a pensar como é construída essa escuta a qual nos referimos acima e de como, através das imagens sonoras, podemos pensar e criar hipóteses sobre os fenômenos estudados.

Percorro a avenida, não sei se aqui ainda é Cel. Marcos ou se já se tornou Av. Wenceslau Escobar. Subindo a lomba, convenço-me, cada vez mais, de que sou uma das únicas a transitar a pé por ali. Os poucos transeuntes desaparecem rapidamente, talvez entrem naquela vila no interior do bairro Vila Conceição. Ouço ônibus subindo e descendo, mas a rapidez com que descem tem uma força que às vezes me assusta, parece que vão me engolir. Subo a lomba e, chegando ao seu topo, entro à esquerda na "entrada principal" da Vila; mergulho em suas ruas de paralelepípedos cobertas por muitas árvores e a cada passo para o seu interior, os sons dos carros e ônibus na avenida ficam num volume mais baixo... Dentro da "calmaria", o canto dos pássaros vai tomando lugar e eu mal ouço os motores dos carros "lá fora". (Trecho de Diário de Campo de Stéphanie Ferreira Bexiga, do dia 16 de março de 2008).

Aquele som do rádio continua, de quem será? Passos e mais passos dos que passam ou param. "CD, DVD!", "Vendo pulseira, pilha...”, um fala e o outro fala, de novo esses dois, o da esquina e do da minha frente, revezam as propagandas de seus produtos. Quase chegando no Mercado Público as sonoridades aumentam de volume e intensidade, e mais uma vez aquela minha hipótese vem à tona: o lojista bate palma, bem forte, para atrair a atenção, e no eco dele, outro recomeça as palmas em uma loja mais a frente, estão ritmados. Este último também segura um microfone, mas sua voz não invade tanto a Rua Voluntários da Pátria, e sim ecoam na Praça XV. (Trecho de Diário de Campo de Priscila Farfan Barroso, do dia 3 de outubro de 2007).

Nesses fragmentos, procuramos identificar de onde (de quem ou de quê) vem essas sonoridades, percebemos que em alguns lugares essas são "mais fortes", ecoam mais, diferentemente de outros, às vezes mais silenciosos ou com a repercussão de outros sons. Como se estivéssemos "mapeando" esses territórios, percorremos os obstáculos da primeira escuta, a causal, e esboçamos os princípios das demais, como procuraremos mostrar adiante.

\section{Sensibilizadas por escutas diversas na construção do conhecimento científico}


Para falarmos dessas escutas, recorremos a Michel Chion (2004) que, preocupado com a classificação dos sons (i-sons, para ele) ${ }^{11}$ relacionado ao contexto cinematográfico, retoma Pierre Schaffer e propõe uma certa "tipologia" de escutas. Nesse sentido, adotamos a idéia de que percorremos algumas destas escutas antes das gravações das sonoridades captadas e mesmo no tratamento posterior ao registro. Mas, como estamos tratando aqui com o que foi definido como pré-campo, temos a intenção de pensar de quais escutas nos utilizamos nessa etapa e o que elas envolvem em termos das preocupações e das intenções de interpretação do vivido urbano.

$\mathrm{O}$ que pode nos revelar, através de diferentes escutas, as constatações das sonoridades existentes numa e noutra rua? Percorremo-las, identificamos a existência de vozes que dialogam, de gritos diversos, latidos de cães, passos apressados, a intensidade (ou não) do trânsito de carros. Recorremos ao diário para descrevê-los e deparamo-nos com uma primeira escuta, a escuta causal, nos termos de Chion. De onde vem esses sons? Quem são essas pessoas que conversam, gritam, param e passam por ali? Através da etnografia de rua e da observação participante ${ }^{12}$ - nós (aprendizes) participamos dessas cenas que se desenrolam nas ruas da cidade. Tentamos "mapear" essas ruas e territórios, procuramos reconhecê-los em termos de suas fontes sonoras, de onde se propagam estes sons; o que existe nesses cantos da cidade? Onde me posiciono para captar esses sons? Pessoas que compram e vendem produtos no espaço público, uma banda toca num lugar próximo, músicas provenientes dos rádios dos carros que passam rapidamente, os passos quase solitários de alguém que entra ou sai de casa numa rua onde só tem residências, assim como o abre-fecha do portão das casas. Preocupa-nos, aqui, as causas destas sonoridades.

Mas nesse percurso também emergem outras interpretações, relacionadas aos diferentes tipos de escutas. Podemos reconhecer os códigos de linguagem que aproximam ou distanciam alguns sujeitos de outros - os ambulantes do centro da cidade, ao serem taxados como ilegais pelos representantes dos órgãos públicos, recorrem às certas "táticas e estratégias" (De Certeau, 1994) para perdurar ali mesmo com as constantes fiscalizações. Quando a Brigada Militar e a SMIC (Secretaria de Municipal de Produção, Indústria e Comércio), por exemplo, se aproxima

\footnotetext{
${ }^{11}$ Ao refutar a idéia de Pierre Schaffer sobre objeto sonoro, Chion constrói a noção de i-som (imagem-do-som) para pensar um fragmento sonoro que não precisa de sua gravação (seu registro nesse tipo de suporte) para existir, e nesse sentido aproximando-se do que afirmamos anteriormente sobre o caráter objetal da imagem sonora. Assim, seu esforço também é de nos sensibilizarmos para a idéia de que o som evoca imagens, por isso a especificação de uma imagem do som.

${ }^{12}$ De acordo com Roberto Cardoso de Oliveira (2000), através da observação participante seria possível captar "excedentes de sentido", ou seja, as significações - que, para nós, se tornam dados - interpretadas "de dentro" da cultura, em sua interioridade da qual o antropólogo faz parte.
} 
dos vendedores, estes se comunicam através de falas, assobios, e avisos que lhe são próprios. Estaríamos tratando de uma escuta semântica para o etnógrafo que procura reconhecer esses códigos de linguagem, em que se "interpreta as piscadelas" desenvolvidas de acordo com o contexto na qual estão situadas.

Nesse sentido, para além das causas as quais também nos preocupamos, nessas escutas já esboçamos interpretações destas sonoridades como capazes de narrar a vida social presente no mundo urbano, voltando-nos, assim, para uma dimensão simbólica destas imagens. Não se trata mais de um caminho direto entre causa e fonte sonora, mas de um pensamento indireto que envolve o aspecto simbólico. Trata-se de uma forma de pensar a cidade ou as "pistas" sobre a cidade, ouvindo, descrevendo, interpretando tais nuances encaminhamo-nos para outro tipo de escuta.

No processo de ida à campo - retorno, escrita, ida - vamos construindo nossas interpretações de acordo com as escutas pelas quais percorremos. Não se trata, no entanto, de uma classificação "dura" onde cada escuta permite apenas certo tipo de interpretação, mas de um trajeto do nosso ouvir, como etnógrafas, que mesmo rompendo com a primeira escuta (a causal, como referido acima), ainda a carrega. E aos poucos durante nossas saídas de campo, passamos a nos preocupar menos com tal causalidade para reconhecermos uma forma assumida por esses conjuntos de imagens sonoras que se propagam nesses cantos de ruas onde realizamos nossas etnografias.

Reconhecemos, então, uma "paisagem sonora" 13 através da escuta figurativa, nos termos de Chion. Para nosso caso, entretanto, preferimos falar em uma "escuta simbólica" por estarmos preocupadas com a imagem sonora como expressão da cultura - diferentemente deste autor. Mas de que forma ela é capaz de narrar a cidade em suas diferentes feições? A partir de uma intenção narrativa, construímos os roteiros para gravação dessas sonoridades nos quais estão elucidadas nossas hipóteses em termos de objeto de pesquisa e da postura a assumir em campo para a captação sonora. Ao conceber o som como objeto possível (e passível) de ser representado, estamos lidando, justamente, com seu descolamento de uma situação particular para pensá-lo como uma representação etnográfica, construída pelo antropólogo.

\footnotetext{
${ }^{13}$ Para Murray Schafer, a paisagem sonora estaria relacionada ao estudo de um ambiente a partir do som (Schafer, 2001, apud Vedana, 2008).
} 


\section{A imagem sonora como dado etnográfico - a construção do roteiro}

As imagens sonoras evocam simbolismos que nos revelam - e nos permitem descobrir os sentidos do viver urbano nas cidades moderno-contemporâneas. Assumida essa perspectiva antropológica, nos perguntamos: mas como ela pode ser uma representação etnográfica, um dado de nossa pesquisa? Afirmamos, anteriormente, que estas imagens são descritas nos diários de campo, dessa forma, constituídas como objeto de representação etnográfica através deste tipo de escrita. Nessas constantes escrituras, de tentativas e dificuldades, de procurar a causa e descrever a fonte, de romper com essa idéia para prosseguir numa descrição que busca interpretar essas imagens, enfrentamos "obstáculos epistemológicos" (Bachelard, 1996) que permitem nosso distanciamento do empírico para, então, construir interpretações sobre o fenômeno. E como representar ou (re) apresentar uma grande cidade através do som?

É desde a indagação do "como fazer" que recorremos aos roteiros e aos "pontos de escuta", trabalhados no interior do BIEV para pensarmos as possíveis formas de etnografar sonoramente esse contexto com o qual estamos lidando. O processo metodológico pelo qual percorremos permite aquele distanciamento (referido acima) e a construção de um roteiro no qual nossas interpretações - hipóteses de pesquisa - vem à tona de forma diferente daquelas dos diários, esboçando aqui nossas intenções de captação. Tendo como premissa que a postura corporal que assumiremos em campo - com o equipamento de som, com os demais sujeitos que participam dessa cena social - está relacionada a uma posição epistemológica de pesquisa ${ }^{14}$, em que construímos o roteiro pensando, imaginando como realizar a gravação. Que cenas, microeventos (Moles, Rhomer, 1982), se desenrolam nessas ruas?

O roteiro de gravação, construído no interior do BIEV e com o qual temos trabalhado, constitui-se de itens que nos exigem pensar a captação em diferentes dimensões. Discutiremos aqui aqueles que consideramos mais importantes em termos da imaginação da captação. ${ }^{15}$

Pesquisa exploratória (tema): Tratando-se de pesquisas no mundo urbano contemporâneo, o que envolve conceitualmente esta gravação? Ao procurar captar os ritmos das sonoridades de uma larga avenida e seu contraste com um canto de bairro "silencioso", quais suas relações -

\footnotetext{
${ }^{14}$ Tal associação, entre posição metodológica e posição epistemológica, é trabalhada neste "Manual" ao qual nos referimos anteriormente (2007, p.08).

${ }^{15}$ Estes elementos (que constituem o roteiro) fazem parte de um roteiro já pré-estabelecido utilizado por outros grupos de trabalho do BIEV.
} 
tensões - com a configuração de uma cidade moderna? Ou, ao estar atenta ao propagandear dos ambulantes numa rua e as constantes fiscalizações dos representantes do Estado para que eles não estejam mais lá, o que esses conjuntos de imagens nos permitem revelar em termos do vivido cotidiano da cidade?

Sinopse (escolha de um objeto): O objeto não é o informante e/ou seu grupo, nem os carros que percorrem a avenida. $\mathrm{O}$ objeto se relaciona ao tema pelo seu viés conceitual e nos faz pensar as expressões sonoras para além de sua causalidade. Dessa forma, para além da escuta causal, o que se constitui como objeto de pesquisa desta gravação?

Argumento (escolha de um universo, contexto): Como é esse universo "de rua"? Quais as pistas que temos de quem os vive no dia-a-dia? Num trecho de avenida passam muitos carros enquanto poucos transeuntes circulam por ali; colada a ela, um pequeno bairro se caracteriza pelo seu "fechamento" em relação à "turbulência" da avenida - que dinâmica de cidade é essa que se desenrola nesse canto?

Roteiro: Como imaginamos percorrer esta rua através da captação do som? Onde nos posicionarmos para evocar certas imagens? Como evocar os diferentes ritmos da avenida onde a volumosa passagem de carros se entrelaça com os passos tímidos dos pedestres? Como será a sequência dessas imagens?

Esse primeiro "núcleo" do roteiro implica em diferentes interpretações do fenômeno para que possamos pensá-lo nas dimensões que envolvem não só o objeto de nossa pesquisa, mas de que situação etnográfica estamos construindo e qual sua relação com o que vai ser gravado em campo. Pensar as sonoridades em sua relação com o cotidiano de viver a cidade, desde um pano de fundo teórico, até aproximá-las do contexto etnográfico, implica pensarmos como interagir com o Outro, em que lugares faremos essa captação - os pontos de escuta -, que tensões são possíveis e como lidar com elas nesse momento. 


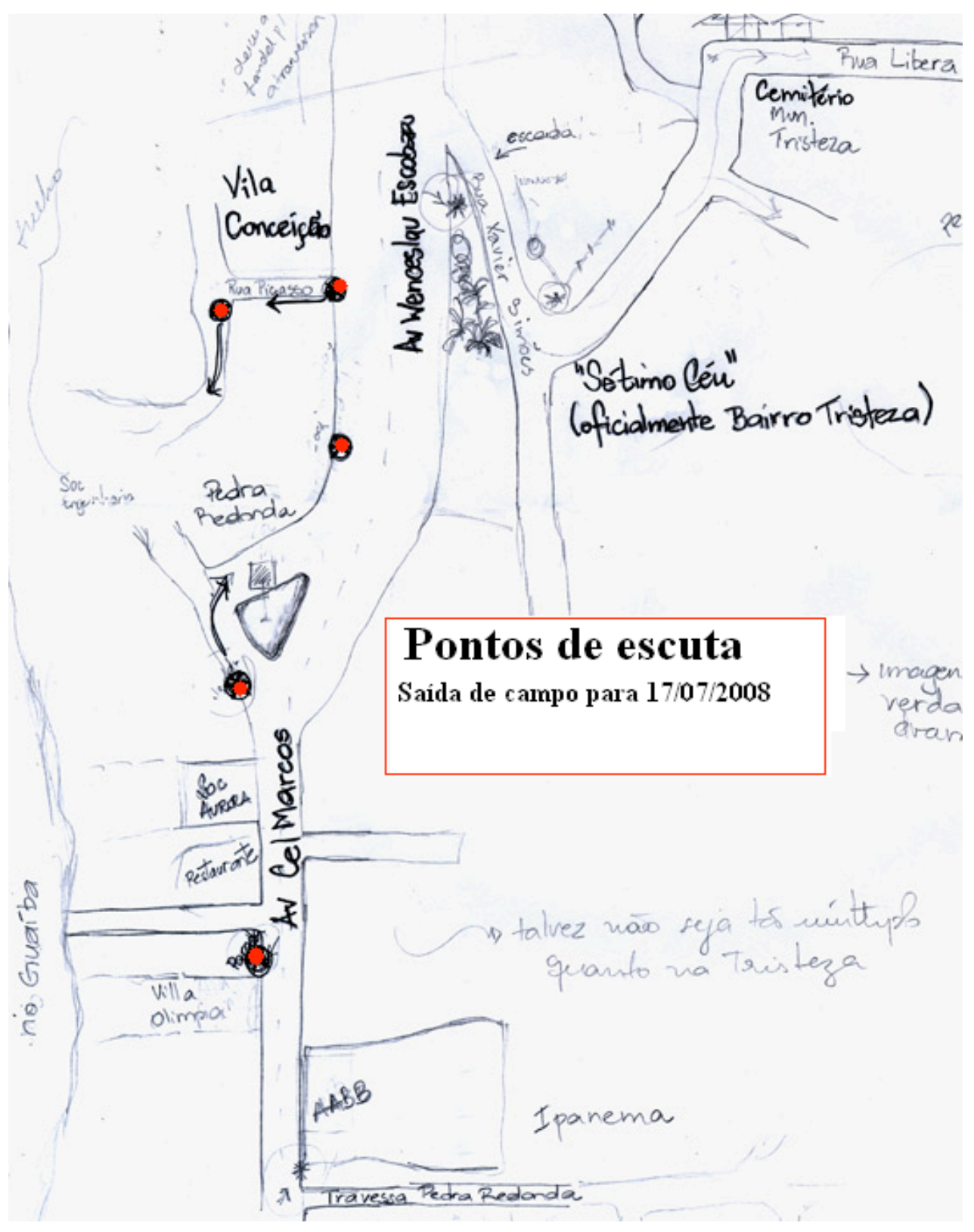




\section{Pré-produção (a construção do objeto)}

\section{Projeto}

\section{Pesquisa exploratória (tema)}

A rua como espaco de trabatho - formas de habitar a rua agenciadas pelos vendedores ambulartes de CD's e DVD's na rua Vohurtários da Pátria. Trata-se de saída de carpo de culbo expbratóno, através das fomas sonoras e visuais que se expressam neste espaço da cidade de Forto Alegre. Esta saída está orientad pela etrografia de rua realizada na Rua Vohurtámos da Pátria tendo ormo foos os vendedores ambulartes, suas perfomances de venda (inchindo aí técnicas corporais e vocais, suas fomas de sociabilidades, redes de relaçōes e condições do trabalho ambularte na rua. Como primeino momerto de captaçäo de imagen em carmo, no sertido do registro sonoro e fotográfioo (tendo em vista que já foram elaboradas escritas e desenhos sobre o fenômeno pesquisado), procura se a descoberta do hugare suas fomas através das soncridades e seu regitro, bem como da produção de imagens fotográficas.

\section{Sinopse (escolha de um objeto) - 1 objeto}

Na complexidade e densidade dos sons da rua, em especial esta Rua do Centro de Porto Alegre por onde circulam rouitas pessoas e também onde traballham outras tantas, com comércio intenso e também diversidade de fomas de sociabilidade e estar na rua, o objeto desta gavação serão prionitariamerte as perfomances orais dos vendedores ambulartes, entendidas nesta pesquisa com "chamamertos". Estes chamamertos apresertam-se como as formas sonoras destes vendedores ocuparemo espaço da rua e corvidarem clientes a realizar uma compra. E clano que daí decoprem outras sonoridades, da roz ou rão, que rão constiluir o orpo sonoro do hugar. Heste caso, os chamamentos podem ser considerados como objeto primcipal da captação sonora, que estarão "enquadrando" outros sons da rua. Para o caso da fotografia, trata-se de inserir esta roz em um cenário, ou seja o objeto neste caso não são tanto os vendedores, mas o oenánio de vendas que conqöem na rua. Esta escollha relacioma-se ao fato de ser uma saída expbratónia que nõo exize aproximação direta em um pimeino momento (mas que também nöo a impede).

\section{Argumento (escolha de um universo, contexto)}

Imagens visuais e sonoras das fomas de trabalho "infomal" na rua Investigar a idéia da rua como "túnel" proposta pela etrografia que vem sendo realizada a partir da densidade das soncridades da rua, compondo camadas de chamamentos, com os fragmertos de falas dos pedestres, as sonoridades dos veículos que circulam por ali e também das bjas que anunciam seus produtos e ofertas. O cenário é a rua e a diversidade de formas de habitála na tertativa de descobrir como isso se expressa no registro sonon e fotográfico.

\section{Roteiro}

Sequências de imagens sonoras dos chamamentos, procurando dar conta de seus ritmos e mebdias, das sobreposiçóes e encadeamentos de amíncios;

Sequências de imazens sonoras que evoquem pedestres, como fragmentos de conversas, passos, irteræçöes com vendedores;

Plamos somoros do tramsito;

Planos somoros das bjas e suas somoridades;

Organização da equipe

dires:̃̃ : Priscila Farfan

captaceñ de som Priscila Forfan

thogafia: Priscila Farfan

montagern e edição: Priscila Farfan

Roteiro de Gravação:

Contato com informantes/instituiçóes se necessário

Etrografia de Priscila Farfin alguns contatos com infomantes já foram realizados indicando a possibilidade de gravação.

Visita às locações

Estudos de iluminação, acústica, horários (ambiente cósmico e social)

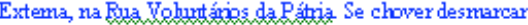

Escolhas de Realização:

\section{Personagens e cenários - informante chave}

Vendedores ambulartes e pedestres, ambiência da rua. Como é saída expbratónia nõo será certrada em um únioo irfomante. E a partir desta saída de canmo

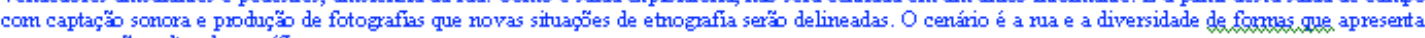
como expressto cultural específica.

Chamamentos: enfocar uma roz em mei a várias voces, enfocar a mitura de vozes (tomadas distintas de som). Estas sonoridades dos chamamertos também evocam outros usos da woz, como as sociabilidades, ocmversas, conflitos, assobios, gritos, enfim, irteraçóes destes sujeitos.

Pedes tres: caminham, conversam, passam, param, oompram. Enfocar vozes e passos, pequenas falas e fragrertos de conversas.

Onibus: o som "do motor" vai irvadir o plano sonous que se está captand. Apresertar o ônubus nõo só peb som do motor que irvade e se ruistura a outras sonoridades, mas também a relaço deste com os "ocupantes" da cidade.

Lojas: vendedor com mino fore ou sem chamando a cliertela.

\section{Dispositivos cênicos}

Caminhadas pela rua acompanhando e distanciando-se de sonoridades especificas

Panticịação na cera da nua irtexação oom habitués na medida em que se aproxinem da equipe.

Contermplação da rua a partir da escolha de alguns portos de escuta e de vista que podem ser adotados a partir dos desenhos e escritas realizados durante a etrografia.

Diálogos com habitués da ruae ambulantes. Possibilidade de corversa infomal

\section{Dispositivos técnicos}

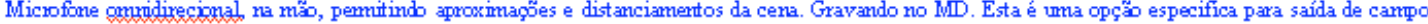
exploxatória

\section{Preparação da equipe de gravação}

\section{Preparação do equipamento |}

MD Bier (baterias ok?)

Mini Disc ( verificar quartidade necessária)

Microfomes - onmidirecional BIEV

Revisão do equipamento e da infra-estrutura (transporte, etc)

Revisar equipamento e separar na reurüo quinta.

Se possível no fin da reurião seria importarte treinar o modo de colocaro equipamerto. 


\section{Imaginar uma gravação através dos dispositivos técnicos, cênicos e dramáticos}

$\mathrm{Na}$ construção do roteiro, há três dimensões fundamentais que perpassam nossas intenções e preocupações em como realizar a captação, elas estão colocadas em termos de dispositivos: técnicos, cênicos e dramáticos. Esses três campos que serão pensados pretendem afastar o pesquisador da indiferença ao realizar a captação, ou seja, cada contexto urbano tem suas especificidades sonoras e ao analisar esses dispositivos estamos descobrindo mais sobre esse lugar na cidade, assim essa preparação antes do campo propõe que se resulte numa maior qualidade no encontro etnográfico.

O recorte conceitual, ao qual nos referimos acima, se constitui como uma das primeiras etapas de distanciamento do contexto etnográfico que será pensado metodologicamente através dessa "tridimensionalidade" dos dispositivos. Esse recorte conceitual está associado à interação com os nossos interlocutores de pesquisa (personagens) e aos cenários de rua, onde se desenrola a vida social da qual participamos ao etnografarmos. Refletir sobre essa captação na dimensão dos dispositivos técnicos significa estarmos preocupadas com a qualidade técnica dessa representação - tradução - da imagem sonora do Outro nos aspectos concernentes aos usos e tipos de equipamentos: que tipo de microfone é mais apropriado para determinada situação? Essa imagem sonora será expressa em sequência? Com cortes? Como se imaginam seus planos sonoros? A opção por um tipo ou a intercalagem deles está vinculada ao contexto etnográfico que experienciamos em nossas saídas de campo.

Na situação etnográfica de uma avenida (Wenceslau Escobar) no bairro Tristeza, que dispositivos técnicos adotar neste contexto onde a calçada é estreita, suas condições tornam difíceis as caminhadas por ali; já os automóveis passam constantemente, alguns com mais facilidade que outros devido à lomba que existe nessa avenida? Opta-se pelo microfone omnidirecional, mas se pretende aproximá-lo da rua dos pedestres, da rua da passagem dos carros, há uma intenção de evocar tanto a amplitude dessa avenida em lomba quando dos roncosos motores - ou seja, em algum momento aproximando-se bastante desses automóveis?

Baseada também nas representações de escritas dessas imagens sonoras, é que nós temos uma idéia quando uma cena social expressada por sonoridades "começou" e em que momento ela se finaliza. Ou seja, ao narrar por sonoridades cenas que evocam os simbolismos da cidade, 
somos influenciados pelos outros encontros com os interlocutores em que ali já pensávamos a representação sonora destas imagens mentais.

Numa rua de comércio popular em que o movimento de transeuntes é intenso, com circulação de carros e ônibus, umas das estratégias para captar as sonoridades referentes às propagandas dos vendedores ambulantes é se posicionar próximo dos informantes que irão elaborar esses "chamamentos". Entretanto quando se aproximam os fiscais da Secretária Municipal de Indústria e Comércio (SMIC), em que os vendedores informais se afastam de seus "pontos", para onde vai a pesquisadora com o seu equipamento? Uma vez que o grupo estudado percorre caminhos invisíveis na cidade, como e onde me situar com o equipamento "chamativo" para não denunciá-los?

Percebemos, assim, que para pensar e escrever sobre os dispositivos técnicos a serem adotados nessa captação, percorremos um espaço vivido, intimamente atrelado aos dispositivos cênicos e dramáticos. As aproximações e distanciamentos imaginados em termos do uso do microfone (por exemplo) estão associadas à nossa relação com o Outro, que implica certos posicionamentos no desenrolar da vida social ligada àquele "cenário urbano". Em que lugares parecem mais expressivas as sonoridades do trânsito de carros contrastada com a de pedestres? Há uma esquina em que é possível ouvir melhor o burburinho do centro da cidade?

Ao captar sons referentes a um espaço vivido, preocupamo-nos com as formas de viver a cidade a partir de seus "microcosmos", em que ali se revelam muitos dos simbolismos constituintes daquela cultura. Esses "espaços" de caráter heterogêneo, às vezes fragmentário, são espaços públicos que permitem sujeitos com interesses diferentes trocarem, se relacionarem de diversas formas. Ali, esses indivíduos são passíveis de tensões diversas e a imprevisibilidade da vida social. Sob o dispositivo dramático, nos cabe pensar os eventos, dramas e imponderáveis da vida social que podem estar em jogo no momento da gravação. Entretanto, ainda que tenhamos o roteiro de gravação com essas estratégias de captação pensadas a partir dos dispositivos, somos constantemente surpreendidas a cada saída de campo desse porte, o que nós permite rever posturas, qualificar ainda mais as descrições dos campos preenchidos no roteiro de gravação e aprofundar o estudo da "etnografia sonora" (Rocha, Vedana, 2007).

O pré-campo, como a primeira das três etapas constituintes do procedimento metodológico que temos desenvolvido no BIEV para pesquisar a cidade através da etnografia sonora, se constitui como um importante momento para pensarmos nossos "a priori" como 
habitantes e pesquisadoras da cidade. No esforço de tornarmos conhecido aquilo que nos é familiar - incluindo-se aí as imagens sonoras com as quais nos deparamos no cotidiano -, recorremos a essa metodologia que nos permite problematizar nossa postura tanto em termos de espaço físico quanto espaço imaginado para realizar uma gravação. Uma postura, e não apenas uma posição, visto que envolve uma adesão epistemológica de pesquisa - nossas escolhas de realização da captação estão, como afirmamos no início deste ensaio, vinculadas à problemática da "duração" (Bachelard, 1988) no estudo das sociedades complexas.

Tendo essa perspectiva como pano de fundo, como a construção do roteiro, através dos dispositivos técnicos, cênicos e dramáticos, pode nos ajudar para gravarmos essas sonoridades? As recorrências de nossas saídas a campo - pela etnografia de rua e sonora e pela observação participante - e de nossas descrições sobre esses fenômenos permitem-nos construir um roteiro que dialogue com este campo, com este Outro que procuramos conhecer. Nesse processo, há a recorrência de nossas escutas, cada vez mais preocupadas em interpretar os significados, as relações dessas imagens sonoras com as pessoas desse lugar. Ao romper com uma escuta causal (ainda que identifiquemos as fontes dos sons) para chegar a uma escuta figurativa, simbólica, reconhecemos uma forma nesse cenário, uma ambiência que lhe é peculiar. Esta é mais um fragmento, mais uma paisagem sonora possível no interior de uma cidade de múltiplas feições.

Assumindo a linha de estudos de sociedades complexas, essa cidade se nos apresenta como um palco que abarca a coexistência de diversas tradições culturais e diferentes visões de mundo (Velho, 1980:16). Ao participarmos e "atravessarmos" essa complexidade buscando interpretá-la através de um conhecimento científico, deparamo-nos com os dramas e estórias humanas depositadas e vividas cotidianamente nesses cenários e que reservam, para nós, mesmo com um "roteiro em mãos", surpresas próprias da dinâmica urbana. Realizar etnografia sonora através da etnografia de rua, como fazemos, é também se preparar para uma situação etnográfica de gravação que pode ser muito diferente de como imaginamos no roteiro, envolvendo os imponderáveis de uma cidade heterogênea. Da mesma forma, aderir a essa metodologia significa orientar nosso ouvir antropológico na pesquisa da e na cidade.

Construídas nas interações entre sujeito e objeto (aqui poderíamos pensar não só em termos do antropólogo e objeto de estudos, mas também nos homens e seu mundo), as imagens simbólicas revelam-nos fragmentos, pistas do viver urbano. Entendidas como dados sensíveis, essas imagens sonoras exigem, também, nossa sensibilização para ouvi-las. Um requisito de 
formação das aprendizes de Antropologia nessa área que através desses procedimentos metodológicos - das escutas e das descrições em diários, de mais escutas e intenções de captação, das escutas e dos dispositivos a serem pensados para fazer a gravação - se orientam no sentido de fazer do familiar, conhecido e, assim, entender que há muito mais por trás dos sons do que nossa primeira escuta revela.

\section{Referências}

BACHELARD, Gaston. A Dialética da Duração. São Paulo, Editora Ática, 1988.

BACHELARD, G. A Formação do Espírito Científico. Rio de Janeiro, Ed. Contraponto, 1996.

BACHELARD, G. A Poética do Espaço. São Paulo, Martins Fontes, 1996.

BIEV, Banco de Imagens e Efeitos Visuais. Manual de Coleções Etnográficas Sonoras. Porto Alegre, 2007.

CERTEAU, Michel de. A Invenção do Cotidiano. Artes de Fazer. Rio de Janeiro, Ed. Vozes, 1994.

CHION, Michel. Le son. Paris, Armand Colin, 2004.

DEVOS, R. ROCHA, A. L. C. Entre constelações de imagens e símbolos convergentes, experimentos no tratamento documental de acervos audiovisuais de narrativas orais. (Apresentação oral no Colóquio "Antropologias em Performance", realizado de 27 a 29 de maio na Universidade Federal de Santa Catarina).

ECKERT, C. ROCHA, A. L. C. Etnografia de rua: estudo de antropologia urbana. In: Revista Iluminuras, $\mathrm{n}^{\circ}$ 07. Porto Alegre: Banco de Imagens e Efeitos Visuais, 2003.

MOLES, H. et ROHMER, E. Labyrinthes du Vécu. L'Espace: matière d'actions. Paris, Librairie des Meridiens, 1982.

ROCHA, Ana Luiza Carvalho da. VEDANA, Viviane. A representação imaginal, os dados sensiveis e os jogos da memória: os desafios do campo de uma etnografia sonora. In: Anais do VII Congresso de Antropologia do Mercosul (VII-RAM), Porto Alegre, 2007, CD-ROOM.

ROCHA, Ana Luiza Carvalho da. Pensar uma Antropologia das profundezas à luz de questões da epistemologia genética. In: Revista Iluminuras, $\mathrm{n}^{\mathrm{o}}$ 03. Porto Alegre: Banco de Imagens e Efeitos Visuais, 2001.

VELHO, Gilberto. Observando o familiar. In: Individualismo e cultura: Notas para uma Antropologia da Sociedade Contemporânea. Rio de Janeiro, Zahar Editores, 1981

VELHO, G. O antropólogo pesquisando em sua cidade: sobre conhecimento e heresia. In: $O$ Desafio da Cidade. VELHO, G. (coord.). Rio de Janeiro, Editora Campus, 1980. 